\title{
Measuring and explaining the diversity of voices and viewpoints in the news
}

\author{
Masini, Andrea ; Van Aelst, Peter ; Zerback, Thomas ; Reinemann, Carsten ; Mancini, Paolo ; Mazzoni, Marco ;
} Damiani, Marco ; Coen, Sharon

\begin{abstract}
News media can be considered to fulfil their democratic role as a "marketplace of ideas" only if they present a diverse content that gives space to a wider range of ideas and viewpoints. But how can content diversity be assessed? And what determines actor and viewpoint diversity in the first place? By employing measurements of actor and viewpoint diversity at the article and newspaper level, this study provides a complete overview on the content diversity of immigration news, and it investigates factors that have an impact on content diversity of immigration newspaper articles in Belgium, Germany, Italy and the United Kingdom (2013-2014). The results of a multilevel analysis indicate that both the articles' size and the elite character of a newspaper play a key role in enhancing news' multiperspectivalness. Also, the findings show that these two measurements of content diversity are different yet related to each other.
\end{abstract}

DOI: https://doi.org/10.1080/1461670X.2017.1343650

Posted at the Zurich Open Repository and Archive, University of Zurich

ZORA URL: https://doi.org/10.5167/uzh-201492

Journal Article

Published Version

Originally published at:

Masini, Andrea; Van Aelst, Peter; Zerback, Thomas; Reinemann, Carsten; Mancini, Paolo; Mazzoni, Marco; Damiani, Marco; Coen, Sharon (2017). Measuring and explaining the diversity of voices and viewpoints in the news. Journalism Studies, 19(15):2324-2343.

DOI: https://doi.org/10.1080/1461670X.2017.1343650 


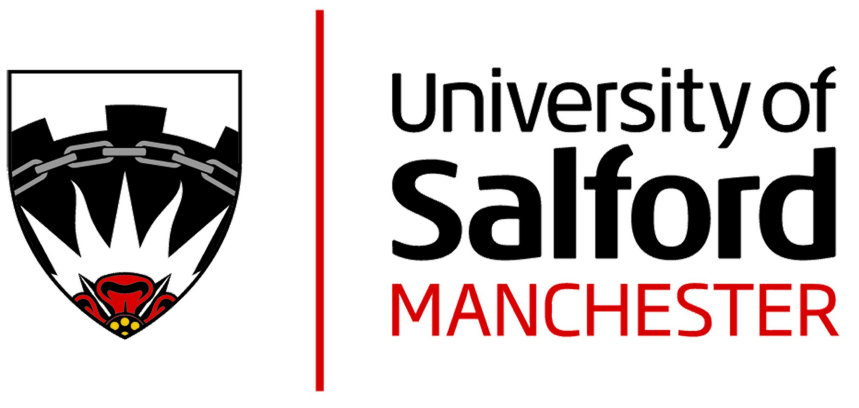

\section{Measuring and explaining the diversity of voices and viewpoints in the news}

Masini, A, Van Aelst, P, Mancini, P, Zerback, T, Teineman, C, Mazzoni, M, Damiani, M and Coen, S

http://dx.doi.org/10.1080/1461670X.2017.1343650

\begin{tabular}{|l|l|}
\hline Title & $\begin{array}{l}\text { Measuring and explaining the diversity of voices and } \\
\text { viewpoints in the news }\end{array}$ \\
\hline Authors & $\begin{array}{l}\text { Masini, A, Van Aelst, P, Mancini, P, Zerback, T, Teineman, } \\
\text { C, Mazzoni, M, Damiani, M and Coen, S }\end{array}$ \\
\hline Type & Article \\
\hline URL & $\begin{array}{l}\text { This version is available at: } \\
\text { http://usir.salford.ac.uk/id/eprint/42608/ }\end{array}$ \\
\hline Published Date & 2018 \\
\hline
\end{tabular}

USIR is a digital collection of the research output of the University of Salford. Where copyright permits, full text material held in the repository is made freely available online and can be read, downloaded and copied for noncommercial private study or research purposes. Please check the manuscript for any further copyright restrictions.

For more information, including our policy and submission procedure, please contact the Repository Team at: $\underline{u s i r @ s a l f o r d . a c . u k . ~}$ 
Measuring and explaining the diversity of voices and viewpoints in the news. A comparative study on the determinants of content diversity of immigration news.

Andrea Masini, Peter Van Aelst, Thomas Zerback, Carsten Reinemann, Paolo Mancini, Marco Mazzoni, Marco Damiani, Sharon Coen

Andrea Masini, Department of Political Science, University of Antwerp, Belgium. Address: Sint-Jacobstraat 2-4, S.LN55.116, 2000 Antwerpen. Tel.: +3232655959. E-mail: andrea.masini@uantwerpen.be. Corresponding author.

Peter Van Aelst, Department of Political Science, University of Antwerp, Belgium. Address: Sint-Jacobstraat 2-4, S.LN55.116, 2000 Antwerpen. Tel.: +3232655723. E-mail: peter.vanaelst@uantwerpen.be

Thomas Zerback, Institut für Kommunikationswissenschaft und Medienforschung, LudwigMaximilians-Universität München, Germany. Address: Oettingenstr. 67, 80538 München. Tel.: +498921809460. E-Mail: thomas.zerback@ifkw.lmu.de

Carsten Reinemann, Institut für Kommunikationswissenschaft und Medienforschung, Ludwig-Maximilians-Universität München, Germany. Address: Oettingenstr. 67, 80538 München. Tel.: +498921809412. E-mail: carsten.reinemann@ifkw.lmu.de

Paolo Mancini, Department of Political Science, University of Perugia, Italy. Address: Area Studi Sociali, Via Elce di sotto, 06123 Perugia. Tel: +39755855409. E-mail: paolo.mancini@unipg.it

Marco Mazzoni, Department of Political Science, University of Perugia, Italy. Address: Area Studi Sociali, Via Elce di sotto, 06123 Perugia. Tel: +39755855428. E-mail: marco.mazzoni@unipg.it

Marco Damiani, Department of Political Science, University of Perugia, Italy. Address: Area Studi Sociali, Via Elce di sotto, 06123 Perugia. Tel: +39755855429. E-mail: marco.damiani@unipg.it

Sharon Coen, Directorate of Psychology and Public Health, University of Salford, United Kingdom. Allerton Building, Salford M6 6PU. Tel.: +4416102957031. E-mail: s.coen@salford.ac.uk

\section{FUNDING}

This work was supported by the University of Antwerp under Grant GOA 28311. 
Measuring and explaining the diversity of voices and viewpoints in the news. A comparative study on the determinants of content diversity of immigration news.

News media can be considered to fulfil their democratic role as a "marketplace of ideas" only if they present a diverse content that gives space to a wider range of ideas and viewpoints. But how can content diversity be assessed? And what determines actor and viewpoint diversity in the first place? By employing measurements of actor and viewpoint diversity at the article and newspaper level, this study provides a complete overview on the content diversity of immigration news, and it investigates factors that have an impact on content diversity of immigration newspaper articles in Belgium, Germany, Italy and the United Kingdom (2013-2014). The results of a multilevel analysis indicate that both the articles' size and the elite character of a newspaper play a key role in enhancing news' multiperspectivalness. Also, the findings show that these two measurements of content diversity are different yet related to each other.

KEYWORDS: comparative research, content analysis, content diversity, journalism, multilevel, news

Word count: 8809

\section{Introduction}

Political communication scholars generally agree that the ideal of a "multiperspectival" press - that is, a press that guarantees access to diverse sectors of society, allowing the presentation of diverse perspectives on a certain issue (Gans 1979, 2011) - is achieved only if news media foster the diversity of their content (Baker 2002; Napoli 1999). As stated by Choi (2009), content diversity is ultimately an indicator of the quality of news reporting. For this reason, both the assessment of diversity and the identification of its determinants are crucial. In which ways can content diversity be exhaustively measured? Under which circumstances can one expect to find higher or lower levels of content diversity? A number of studies in the field have attempted to conceptualise and measure news content diversity (Benson 2009; Carpenter 2010; Choi 2009; Humprecht and Büchel 2013; Voakes et al. 1996). Yet, this research has proven elusive in defining and employing different measurements of content diversity and, 
with a few exceptions (see Benson 2009; Humprecht and Büchel 2013), it has neglected to investigate the factors that make the content more or less multiperspectival.

Drawing upon a comparative cross-country content analysis of the news coverage of immigration in four European countries (Belgium, Germany, Italy and the United Kingdom), this study aims at systematically examining the impact of different factors on news content diversity. According to Benson $(2009,403)$, the issue of immigration is suit for the analysis of variation in the diversity of news content, as it is a "multifaceted and complex" topic that is typically disputed by a broad range of social actors, willing to put forward their viewpoints in the news in order to influence public opinion.

The paper will proceed as follows. After having provided an exhaustive conceptualisation of content diversity, we present a model to identify the factors that might shape news content diversity, and we present hypotheses on the direction of these influences. Then, we explain the methodological choices that have been made to measure content diversity and gauge the impact of the factors affecting the level of multiperspectival reporting. Finally, we present our findings and discuss them in light of the democratic role of the media.

\section{Theoretical framework and hypotheses}

\section{Conceptualisation of content diversity}

As noted by van Cuilenburg $(1999,188)$, content diversity corresponds to the "heterogeneity of media content in terms of one or more specified characteristics". For example, media content can vary according to the issues or the news stories that are presented (Carpenter 2010, Humprecht and Büchel 2013), news genres, geographic locations (Choi 2009), etc. This study investigates the variety of two of the most important elements of news content, namely social actors and viewpoints. As noted by Benson and Wood (2015), the analysis of voices in the news is a central concern for journalism studies, in that actors' ability to speak in the news is key to shape the debate on a certain issue. However, as the authors argue, their ability to express viewpoints on the issue under discussion is what really allows them to contribute to the framing of a topic. In the words of Griswold (1998), it is the diversity of viewpoints that can provide readers with a wide range of perspectives on a given issue. This conceptualisation, originally proposed by McQuail and Van Cuilenburg (1983), it is similar to the one used by Baden and Springer (2015) and by Benson $(2009,406)$, who defines content diversity in terms of "institutional" and "ideological multiperspectivalness". Similarly, Voakes et al. (1996) examine content diversity as the variety of news sources and the dispersion of viewpoints in the news.

Moreover, the conceptualisation of content diversity differs according to the level of analysis. Diversity can be measured at the level of the single unit of information - like a TV news item or a newspaper article - as the variety of different social actors and viewpoints that are represented therein. Alternatively, it can be gauged at a broader level as the evenness of the distribution of these two dimensions within a news outlet - like a TV news broadcast or a newspaper - throughout a specific period of time. The difference between both levels is more than a technical measurement distinction and suggests a different way that a news consumer learns about an issue. If we focus our measurement on the article level, diversity implies that each story should give space to several types of actors and/or to multiple viewpoints. Only in this way, when reading a single news item, a reader gets a broader understanding of the issue. However, a news outlet can also guarantee content diversity by portraying different actors and viewpoints in different news items. Benson $(2009,2013)$ notes that this is a typical characteristic of the French "debate ensemble" form of news: for French journalists it is not 
the single article that matters, but the entire "page", which includes, for example, an interview with the minister of immigration alongside an article telling the personal story of an immigrant family entering the country. In this case, both stories together provide the reader with multiple perspectives, while on the article level the diversity of actors and opinions is limited.

Since these measurements of content diversity yield different values, extant studies that focus exclusively on one level convey a rather incomplete picture of the diversity of news content. This study seeks to overcome this inadequacy by mapping and comparing how newspapers perform in actor and viewpoint diversity both at the article and at the newspaper level. Also, we shed light on the relationship between measurements at both levels through the analysis of the determinants of content diversity, which is central to this paper. Do different factors have the same impact on content diversity measured at the article and at the newspaper level? To this purpose, in the next section, we introduce a conceptual model including the main factors that might influence actor and viewpoint diversity in the news.

\section{Defining a Multilevel Model of Influence on Content Diversity}

Although there is a long tradition of research on the diversity of news (e.g. [Benson 2009]; [Carpenter 2010]; [Choi 2009]; [Humprecht and Büchel 2013], [Voakes et al. 1996]), two recent journalism studies explicitly focus on the determinants of news' content diversity. Drawing upon Bourdieu's field theory (Bourdieu and Wacquant 1992), Benson (2009) argues that content diversity of immigration-related news in France and the U.S. is shaped by the interaction of the journalistic field with the political and economic fields, as well as by features of the journalistic field itself. Within the political field, the characteristics of the party system, along with governmental policies on press regulation and subsidies, might have an impact on content diversity. Concerning the economic field, advertising support is considered to play a key role in shaping actor and viewpoint diversity. Finally, moving to the journalistic field, the author observes that content diversity might be shaped through the formats in which news is presented, as well as by the cultural capital of newspapers and their audiences. In a more recent study on the online reporting of the "Occupy" movement, Humprecht and Büchel (2013) draw on Shoemaker and Reese's (1996) "Hierarchy-of-Influences Model" and define a pattern to identify factors at the national and organisational level that might explain variations in content diversity. At the national macro-level, they examine the influence of the relevance of the topic, as well as that of macroeconomic variables, on content diversity. At the organisational meso-level, the authors analyse the role played by the resources of the news organisation and its orientation towards quality journalism.

Building on the multilevel approach of these contributions, we aim to define a model that pinpoints the levels in which forces that shape content diversity are located. The idea, drawn from the hierarchical approach proposed by Shoemaker and Reese (1996), is that news content - the final outcome of the journalistic process (Carpenter 2010) - is embedded in multiple spheres of influence corresponding to the different levels that shape news production (Figure 1).

[Figure 1 near here] 
At the micro-level, the article format - i.e. its length and type - might affect content diversity, while at the meso-level the characteristics of the news organisation, namely its size and the preferences of its target audience, can influence actor and viewpoints diversity. Finally, at the macro-level, countries' characteristics belonging to the journalistic and issue-specific dimensions, are potential driving forces behind the diversity of immigration news. In the following sections, we formulate hypotheses on the influence of these factors on content diversity of immigration news.

\section{Influence of article's characteristics: length and type}

The theoretical foundations that formal characteristics of communication might have an influence on the content go back to ancient philosophy. Plato observed that the forms of human conversation (which we can conceive in the broader sense of mediated communication) can determine the content that is expressed. As our study encompasses just one medium, namely newspapers, we do not think of "form" as medium type. Instead, we examine the way in which information is organised and presented to the newspaper's readers (Altheide 1985; Barnhurst and Nerone 2001). Previous research on the deliberative quality of televised messages (Bourdieu 1996; Postman 1985; Sartori 1997) concludes that television's time constraints jeopardise the articulate rational character of media discourse. Likewise, space constraints in the print press might affect content diversity: in the presence of shorter articles, the space for the expression of different social actors and arguments is reduced. This question has been explored by Humprecht and Büchel (2013), who find that the length of online news articles about the Occupy movement is a key element in allowing for higher levels of diversity. Hence, we posit the following hypotheses:

Hypothesis 1: The length of articles about immigration has a positive effect on the levels of actor diversity (1a) and viewpoint diversity (1b).

Furthermore, we argue that the type of article might also play a key role in shaping content diversity of news about immigration. Based on a deductive analysis, we distinguish between six main article types: news reports, special reports, editorials, opinion articles, interviews and letters from readers. We argue that differences in the "primary purpose" of these news types might have an impact on content diversity. On the one hand, editorials, opinion pieces, interviews and letters from readers are more opinionated article types that have the primary aim to convey a particular point of view (of the journalist or another agent) about the issue under discussion. On the other hand, news reports and special reports are more informative types that mainly provide the reader with an account of facts. When writing articles of this kind, journalists are more likely to follow the principle of objectivity, which is the "defining norm of modern journalism" (Patterson 1998, 28), by promoting the representation of diverse actor and viewpoint categories. Nevertheless, we have to recognise that special reports have the specific goal to provide an in-depth account of a topic, usually by covering opposing voices and different ideas, which makes them the most suitable article type to promote content diversity. Hence, we hypothesise that:

Hypothesis 2: Special reports about immigration enhance the levels of actor diversity (2a) and viewpoint diversity (2b), as compared to news reports. On the contrary, more opinionated news types about immigration decrease the levels of actor diversity (2c) and viewpoint diversity (2d), as compared to news reports.

\section{Influence of newspaper's characteristics: size and audience's cultural capital}


In order to study influences at the meso-level, we start from Reese's (2001) assumption that the news is the product of an organisation that is driven by specific goals, and has a certain structure to enforce them. Simply put, at this level we consider the capability and the will of a newspaper organisation to foster content diversity. Previous studies have noted a positive relationship between the newspaper's size and its capability of providing a multiperspectival reporting. Humprecht and Büchel (2013) find that the dimensions of a news organisation in terms of its human resources - i.e. the number of journalists working for it - matters in enhancing content diversity. We argue that the size of a newspaper is the combination between the scope of the outlet and the dimensions of its staff, with the former often (but not always) determining the latter. Local newspapers are considered "small" because of a more limited geographical scope, which typically results in a smaller staff covering a narrower range of events at the local level. By contrast, national newspapers are "big" as they have to deal with a wider array of events and actors at the national and international level. Although there are examples of local newspapers having larger newsrooms than national ones, we expect that in general the latter will employ more journalists to cover a greater geographical scope. This is even more likely if we consider that the crisis of the media sector has hurt local news organisations the most, forcing them to impose significant staff cutbacks (Franklin and Murphy 1998). Consequently, we expect that "big" national newspapers provide a more diverse coverage of the issue of immigration than "small" local newspapers. For example, we expect that national news outlets will rely more on foreign correspondents to enhance geographic proximity when covering key events related to immigration, or to gain direct access to the voice of international politicians (e.g. in Brussels or in Washington), thereby increasing the chances of providing more content diversity compared to local papers. Also, due to their bigger weight in the national media landscape, national outlets are usually granted a preferential channel to reach various key actors in society (experts, politicians, members of international organisations, etc.) and include more diverse opinions in the news. A formal test of the relationship between a newspaper's size - in terms of its circulation - and the diversity of its content is done by Voakes et al. (1996), but they find that smaller newspapers do not display lower levels of content diversity. Nonetheless, because these results might be biased by the local scope of their study, we still expect the following:

Hypothesis 3: Immigration news in national newspapers will have higher levels of actor diversity (3a) and viewpoint diversity ( $3 b)$, as compared to local newspapers.

Furthermore, we argue that the will of a newspaper to foster content diversity depends on its editorial orientation in order to match the "cultural capital" of its target audience (Benson, 2009, 405). Literature on economic explanations of news construction demonstrates that newspapers are able to attract readers based on the audience's cultural preferences (Baron 2006; Callaghan and Schnell 2001; Gentzkow and Shapiro 2010; Hamilton 2004). According to Peterson and Kern (1996), the "omnivorousness" of cultural tastes - i.e. a cultural appetite for a diverse range of cultural production - is a key characteristics of highbrow audiences, as opposed to the more limited range of preferences typical of middlebrow and lowbrow audiences (see the definition of [Levine 1988] and [DiMaggio 1991]). In line with this, Benson (2009) suggests that elite newspapers targeting a highbrow audience are likely to promote diversity of their content in order to match the more "omnivorous" predisposition of their readers, whereas popular newspapers targeting more middlebrow and lowbrow readers deliver a less complex, less diverse content. Consistent with this, Roggeband and Vliegenthart (2007) notice that when covering immigration and integration Dutch newspapers targeting an elite audience make use of more diverse frames compared to outlets with a more popular readership. Thus, we hypothesise the following: 
Hypothesis 4: Immigration news in elite newspapers will feature higher levels of actor diversity (4a) and viewpoint diversity (4b), as compared to popular newspapers.

\section{Influence of country-related characteristics: journalistic dimension and Lampedusa}

Finally, this study explores inter-country variation in the levels of content diversity. Crossnational differences in news content diversity have been investigated by Esser and Umbricht (2013) within a broader longitudinal study on the objectivity paradigm within Western press systems. Their findings show that the inclusion of opposing viewpoints in political news which is an indicator of content diversity - was the lowest in Italy, while the results for the British press are aligned with those of countries belonging to the Democratic-Corporatist model (Hallin and Mancini 2004), namely Germany and Switzerland. Furthermore, as observed by Martin (1988) and Choi (2009), geographic proximity to the key locations where an issue is unfolding enhances media's potential to provide a diverse coverage of the topic. During the period under study, according to the EU-agency Frontex, over 200.000 migrants have entered Europe by sea through the Italian island of Lampedusa. As observed by Cuttitta (2014, 196), the island has become the symbol of migration into Europe, as well as the "theatre of the 'border play'”, a figurative stage in which a large array of social actors debate on migration control (De Swert, Schacht, and Masini 2015). Contrary to the negative effect on content diversity stemming from its journalistic characteristics, geographic proximity to this relevant place for immigration - both in its real and symbolic dimensions - might correspond to a more diverse coverage of immigration in Italian newspapers. We will thus investigate the interplay between these two opposing forces.

\section{Data and methods}

This study analyses news about immigration in a sample of newspapers in Belgium (Flanders), Germany, Italy and the United Kingdom, between 1 January 2013 and 30 April 2014. The newspaper sample includes 22 titles with a large variation in terms of national/local scope and audiences' cultural preferences (see Appendix 1). For Belgium, we selected six news outlets from Flanders, the Dutch-speaking community: De Morgen, de Standaard, De Tijd, Gazet van Antwerpen, Het Nieuwsblad and Het Laatste Nieuws. The German sample includes five titles: Die Welt, Berliner Morgenpost, Der Tagesspiegel, Süddeutsche Zeitung and Stuttgarter Nachrichten. In Italy, we selected five outlets: La Repubblica, Gazzetta di Modena, Il Giornale, Il Messaggero and Il Mattino. Finally, for the UK, we chose The Times, The Independent, The Sun, Daily Mirror, Manchester Evening News and London Evening Standard.

Through a Boolean string, translated in every language of interest, we searched in online databases articles about immigration, this being defined as the entrance and the presence of people in a country other than their country of birth with the purpose of settling down (drawn from the United Nations' definition of immigration). This all-encompassing search criterion allows us to grasp the different aspects of the multifaceted and evolving phenomenon of immigration, therefore ensuring comparability among countries and across time. The outcome of the first search for the whole period was further filtered, and ultimately resulted in a final sample consisting of 2490 news articles (642 for Belgium, 484 for Germany, 822 for Italy, 542 for the UK). The items were coded quantitatively by coders based in each country of the study. Extensive training was provided by a master coder in every country in which the coders' teams were based. Intercoder reliability was tested for each country on a $10 \%$ subsample. For the variable indicating the article type, Krippendorff's alpha scores range from 0.93 to 1 in the four countries. The scores concerning the actor variables range from 0.62 to 1 , with an average of 0.78 , and coefficients of the variables 
indicating viewpoints range from 0.60 to 0.66 . Because alpha is sensitive to skewed variables (as it is the case for actors and viewpoints, which present a large amount of missing values), we also calculated the percentage of intercoder agreement with Holsti's formula (Holsti 1969). For actors, Holsti's scores range from 0.70 to 1 , with an average of 0.87 , while they range from 0.88 to 0.96 for the viewpoint variables (average 0.92 ). On top of it, we calculated intercoder reliability across countries on a smaller subsample of articles in English, with overall satisfying results.

A maximum of 10 quoted or paraphrased actors were coded in every article. Actors were identified by codes corresponding to different actor groups in society (see Graph 1 in the Results section). As we are mainly interested in the diversity of social groups that enter the news, all national political actors were considered as one group. In contrast with studies on political balance, we do not focus on the presence of different types of politicians, but rather on the attention for politicians versus all other type of actors that are involved in the immigration debate. Besides, coders indicated the presence of "Viewpoints about immigration and immigrants" in every news item. Based on existing literature on viewpoint and frames regarding immigration (e.g. [Benson 2009, 2013]; [Van Gorp 2005]) we distinguished between four types of distinct viewpoints, that were operationalised as dummies ${ }^{1}$ :

- Negative: Negative characterisation of immigrants/immigration (e.g. immigration is bad for the economy, immigrants carry diseases, they commit crimes, etc.)

- Administrative burden: Immigrants (or immigration) are seen as creating administrative problems (e.g. concerns about the management of the arrivals, food supply, hygiene, etc.)

- Victimisation: Immigrants are portrayed as victims (e.g. immigrants are victims of unjust government policies, traffickers, they have to deal with racism/xenophobia, etc.)

- Positive: Positive characterisation of immigrants/immigration (e.g. immigration empowers work force, enhances "positive multiculturalism", immigrants work hard, etc.).

Starting from these variables, we measure content diversity both at the article and at the newspaper level. At the article level, actor diversity is a count variable - ranging from 1 to 10 - corresponding to the total number of social categories that are represented in an article. Viewpoint diversity, also a count variable, corresponds to the total number of different viewpoints that are expressed in the article, and it ranges from 1 to 4 . It is important to note that articles that do not feature any actor or viewpoint are excluded from the analysis. Instead of representing the lowest level of diversity, we argue that articles of this kind are neutral because all voices and views on immigration are absent. Only if an article provides at least one actor or viewpoint, it is worth analysing how diverse the range of actors and viewpoints is. At the newspaper level, actor diversity is measured as the evenness of the distribution of the total number of actors in the corresponding categories. The same is done for viewpoint diversity. This is calculated by means of Simpson's standardized diversity index $\left(D_{z}\right)$, a standardized calculation of Simpson's diversity index (D). Although Simpson's measure of content diversity is sensitive to the number of categories that are included in the calculation, we keep this sensitivity to a minimum by using its standardized version, which is more

\footnotetext{
${ }^{1}$ Negative and Positive viewpoints derive from more fine-grained categories that were originally coded, namely "Immigration/immigrants as a general threat", "Immigration/immigrants as an economic threat", "Immigration/immigrants as a cultural/moral/ethnic demographic threat" - which were collapsed in the negative viewpoints category -, and "Immigration/immigrants as a general opportunity", "Immigration/immigrants as an economic opportunity", "Immigration/immigrants as a cultural/moral/ethnic demographic opportunity" - which were collapsed in the positive viewpoints category.
} 
suitable to compare diversity values across distributions comprising different numbers of categories (Mcdonald and Dimmick 2003). The formula for Simspons's $D_{z}$ is:

$$
D_{z}=\frac{1-\sum p_{i}{ }^{2}}{1-\frac{1}{k}}
$$

where $p_{i}$ is the proportion in the ith category, categories $=i$ through $k$ is the number of categories in the distribution. Simpson's $\mathrm{D}_{\mathrm{z}}$ ranges from zero to one. In the case that the entire population belongs to one category (i.e. lowest level of diversity) the score would be zero. The greater the extent to which the population is evenly distributed among the categories, the closer the score will be to one.

Moving on to the determinants of content diversity, the length of an article is an ordinal variable including the values $1=$ very short (less than 200 words); $2=$ short (between 201 and 400 words); $3=$ medium (between 401 and 600 words); $4=$ long (more than 601 words). These cut-off points were established following an inductive analysis of the length of articles in each country under study. The variable "article type", encompasses three categories: news report, special report and "opinionated news type". The last category includes editorials, opinion pieces, interviews and letters of readers. Moreover, newspapers' orientation towards a highbrow, middlebrow and lowbrow audience was defined based on the extant literature, as well as on national experts' judgements. We grouped lowbrow and middlebrow newspapers together, and created a dummy variable with one category indicating elite newspapers and the other one for popular outlets. Likewise, the national/local character of a newspaper was operationalized as a dummy variable.

In the following section, we present the results of the study. Measurements of actor and viewpoint diversity at the article and newspaper level are presented and compared. Moreover, we test the influence of the different factors on content diversity. For diversity measured at the newspaper level, we test the influences of articles' and newspapers' characteristics separately, by means of a set of linear regressions, and we explore a pattern of intercountry differences by comparing the scores. For this test, the determinants at the article level - length and article type - are operationalised as dummy variables. The first dummy measures whether a newspaper has a majority of long or short articles. It is constructed by subtracting the sum of very short and short article from the sum of medium and long articles. Positive values show that there are more medium and long articles in the newspaper (category "newspaper with a majority of longer articles"). By contrast, negative values indicate that there are more short and very short articles in a newspaper (category "newspaper with a majority of shorter articles"). Similarly, the second dummy shows if a newspaper employs more special reports than opinionated news articles such as editorials, opinions, interviews and letters to the editor. We define special reports as articles that aim at giving insights into a specific topic, characterised by an in-depth angle on the issue, and that are generally longer than news reports. We subtracted the average of the proportions of opinionated news types from the proportion of special reports, holding the proportion of news reports constant. Positive scores indicate that this is a "newspaper with a higher proportion of special reports", whereas negative scores show that this is a "newspaper with a higher proportion of opinionated news types". In order to test the impact of the determinants of the article-based measurements of diversity we have to use either a Poisson or a negative binomial regression model, because of the count nature of the dependent variables. We tested the assumption of equidispersion, which does hold, and therefore selected the Poisson regression model. Finally, 
to account for the clustering of the articles in countries, we add country dummies to the model.

\section{Results}

Before we test for the factors that influence content diversity, we present descriptive results of the actors and viewpoints in the news in the four countries under study. Graph 1 shows that the distribution of social actor categories is very similar across countries. Not surprisingly, national politicians are the most quoted or paraphrased social group in every country of the sample (ranging from 53\% of total actors in Italy to $32 \%$ in Belgium). After national and international political actors, space is given in all countries to ordinary people and public opinion voices, followed by immigrants and civil society actors. The relative low presence of immigrant voices, the real protagonists of immigration news, is similar across countries, ranging from $11 \%$ of total actors in Belgium to $7 \%$ in the UK. We also note that actors from the business, corporate and finance sectors were all but visible in the news.

[Graph 1 near here]

If we exclude those news items that do not feature any actor (not presented in table), each article features on average less than two social categories $(\mathrm{N}=2138)$. Almost half of the articles include just one actor category (49\%), while 29\% feature two actor categories, $15 \%$ present three and $6 \%$ four different social categories. When articles give voice to just one type of actor $(\mathrm{N}=1047)$, this is the "national politicians" category in $51 \%$ of the cases, and in $14 \%$ that of "international politicians", whereas in just $6 \%$ of the cases immigrants are the one and only voice in an article. When the range of actors talking in an article opens up, national politicians are very likely to be included. Most of the articles that give voice to two social groups $(\mathrm{N}=609)$, combine national political actors with public agencies $(13 \%)$, or with civil society actors $(11 \%)$, or with international political actors (also $11 \%$ ). Finally, national politicians talk in combination with immigrants in $4 \%$ of the cases. Even when an article includes three different social categories $(\mathrm{N}=317)$, the most recurring combinations feature national politicians: either with immigrants and ordinary people $(9 \%)$, or with public agencies and ordinary people (7\%), or with public agencies and civil society actors (7\%).

Similarly, $65 \%$ of the articles that express viewpoints on immigration $(\mathrm{N}=1809)$ present just one type of viewpoint, while $29 \%$ feature two distinct viewpoints. Only $3 \%$ of the total articles give space to three or four different viewpoints. Single-viewpoint-articles $(\mathrm{N}=$ 1204) mostly give space to the representation of immigrants as victims (43\%). In $28 \%$ of the cases, the article is fully negatively slanted, and in $15 \%$ of the cases it just deals with the administrative problems arising from immigration. Finally, just $14 \%$ of the articles are exclusively positively slanted. The victimisation category prevails also when the article includes more than one viewpoint. When two viewpoints are presented $(\mathrm{N}=539)$, we mostly find a combination of victimisation with positive viewpoints $(30 \%)$, while fewer articles combine victimisation viewpoints with the view of immigration as an administrative burden $(21 \%)$, or with negative viewpoints $(18 \%)$. Truly balanced stories on immigration presenting both negative and positive viewpoints are rather exceptional (11\%).

Measurements of content diversity 
We now move to a closer analysis of the measurements of content diversity at both the article and the newspaper level. Our results show that newspapers include on average less than two different actor categories per article, excluding those that have no actors $(\mathrm{M}=1.82, \mathrm{SD}=$ 0.24 ), which gives the idea of a rather low actor diversity. On the contrary, actor diversity scores calculated with Simpson's $\mathrm{D}_{\mathrm{z}}$ are on average close to one $(\mathrm{M}=0.82, \mathrm{SD}=0.07)$, which corresponds to a well-balanced distribution of social actor categories in each outlet. This seems to be at odds with the aggregate actor distribution displayed in Graph 1, pointing to an overrepresentation of national politicians in the news sample. However, the result is mostly driven by the evenness of the distribution of the other actor categories. If we run a robustness check by excluding national politicians from the analysis, the average Simpson's $\mathrm{D}_{\mathrm{z}}$ score is even closer to one $(\mathrm{M}=0.92, \mathrm{SD}=0.03)$. Moving the attention to the viewpoints, newspapers present a rather limited average of 1.36 categories per article, if we exclude those with no viewpoints $\left(\mathrm{SD}=0.11\right.$ ). Nonetheless, as observed for actor diversity, $\mathrm{D}_{\mathrm{z}}$ viewpoint diversity scores are close to 1 , which means that the distribution of the four types of viewpoints is well balanced for each newspaper over the period $(\mathrm{M}=0.89, \mathrm{SD}=0.08)$. To sum up, these findings support the first broad assumption of this paper: measurements of content diversity at different levels yield different results, and provide a different evaluation of content diversity. Nevertheless, we also find a significant positive correlation between the scores of actor diversity at the article level and $\mathrm{D}_{\mathrm{z}}$ scores for actor diversity at the outlet level, $(\mathrm{r}=0.592, \mathrm{~N}=22, \mathrm{p}=0.004)$, and a weaker correlation between the two levels of viewpoint diversity scores, $(\mathrm{r}=0.473, \mathrm{~N}=22, \mathrm{p}=0.026)$, which suggest a moderate positive relationship between measurements of content diversity at the article and at the newspaper level. Put differently, newspapers that cover immigration in a more diverse manner within their articles also tend to score higher in their coverage as a whole.

Another suggestion that diversity measurements at the article and newspaper level might be related to each other is given by Table 1, which displays the variation of actor and viewpoint diversity according to different factors. In most of the cases, although differences are minimal, we detect similar effects for outlet- and article-based scores. At the micro-level, ANOVA tests show that longer articles give significantly more space to different actors and viewpoints (respectively, $\mathrm{F}(3,2131)=92.574, \mathrm{p}=0.000$, and $\mathrm{F}(3,1801)=12.743, \mathrm{p}=0.000$ ). Likewise, newspapers with a majority of longer articles present higher $\mathrm{D}_{\mathrm{z}}$ scores for actor diversity and viewpoint diversity, as compared to those with a majority of shorter articles, but independent $\mathrm{t}$-tests show that this difference is significant just for actor diversity $(\mathrm{t}(20)=$ $3.357, \mathrm{p}=0.003$ ). Concerning the influence of the type of article, special reports present a significantly broader range of actors and viewpoints than news reports, and the latter score significantly higher than opinionated news types (respectively, $\mathrm{F}(5,2113)=38.005, \mathrm{p}=0.000$, and $\mathrm{F}(5,1788)=5.116, \mathrm{p}=0.000$, ANOVA tests). Similarly, newspapers in which special reports are predominant present a more balanced distribution of actor and viewpoints categories than those with more opinionated article types. By contrast, we notice that opinionated articles feature more viewpoint categories than news reports. However, for $D_{z}$ scores, neither of these differences are statistically significant $(\mathrm{p}>.10)$.

Focusing on the determinants at the meso-level, Table 1 shows similar effects for both measurements of content diversity. National newspapers score slightly higher than local outlets in actor diversity. The results of independent t-tests indicate that this difference is significant for $D_{z}$ values of actor diversity $(t(20)=2.113, p=0.047)$, but not for measurements at the article level $(\mathrm{p}>.10)$. Local newspapers perform better than national ones in viewpoint diversity, but the differences are not significant for neither types of measurements $(\mathrm{p}>.10)$. On top of it, the difference between elite and popular newspaper is statistically significant for actor diversity (for article level measurements, $t(1428)=-5.422, p$ 
$=0.000$, for $\mathrm{D}_{\mathrm{z}}$ scores, $\left.\mathrm{t}(20)=-2.541, \mathrm{p}=0.019\right)$, and it is larger than the difference in viewpoint diversity, which is nonetheless not significant $(\mathrm{p}>.10)$. Finally, regarding the macro-level, the table shows that, for both measurements, Italian newspapers display the lowest levels of actor diversity, while UK outlets present the highest extent of viewpoint diversity. As demonstrated by ANOVA tests, inter-country differences are statistically significant for actor diversity (both for values calculated at the article level, $\mathrm{F}(3,1805)=$ 2.494, $\mathrm{p}=0.000$, and for $\mathrm{D}_{\mathrm{z}}$ scores, $\left.\mathrm{F}(3,18)=4.265, \mathrm{p}=0.019\right)$, but not for viewpoint diversity (article level, $\mathrm{p}>.05, \mathrm{D}_{\mathrm{z}}$ values, $\mathrm{p}>.10$ ).

[Table 1 near here]

\section{The determinants of content diversity}

We now move to a multivariate test of the determinants of actor and viewpoint diversity measured at the article level to identify the original influence of single factors while controlling for others. Model 1a (Table 2) shows that the article's length is significantly, positively related to actor diversity $(p<.01)$. The influence of articles' types on actor diversity is in line with our expectations, in that special reports have a significantly higher level of actor diversity compared to news reports $(\mathrm{p}<.01)$, whereas opinionated article types score significantly lower than news reports in actor diversity $(\mathrm{p}<.01)$. Model $1 \mathrm{~b}$ shows that the elite character of a newspaper has a significant positive impact on actor diversity $(p<.05)$ when not controlling for article's characteristics. Moving the focus on the determinants of viewpoint diversity, Model 2a shows that long articles, and to a lesser extent, medium articles correspond to a significantly broader range of viewpoints expressed in the article (respectively, $\mathrm{p}<.01$ and $\mathrm{p}<.05$ ), while short articles do not present significantly higher viewpoint diversity levels than very short articles $(\mathrm{p}>.10)$.

[Table 2 near here]

Moving to a test of the determinants of content diversity calculated with Simpson's $D_{z}$, the results of a linear regression show that the articles' length has a significant positive effect on actor diversity $(\beta=0.66, p=0.005)$, while the effect of articles' type is not significant $(p=$ 0.550). However, neither articles' length, nor the type have a significant effect on viewpoint diversity (respectively, $\mathrm{p}=0.240$ and $\mathrm{p}=0.908$ ). Besides this, we find signs that newspapers' characteristics matter in shaping actor diversity. Elite newspapers present significantly higher actor diversity than popular outlets $(\beta=0.44, \mathrm{p}=0.026)$, and the effect stemming from the size of a newspaper on actor diversity is close to the significance level $(\beta=0.36, p=0.061)$. Nevertheless, there is no significant difference between national and local newspapers in viewpoint diversity ( $p=0.105$ ), nor is there a significant effect related to the audience's cultural preferences $(\mathrm{p}=0.434)$.

To sum up, at the micro-level, length matters in shaping actor diversity (both calculated at the article and newspaper level), therefore giving full support to Hypothesis 1a. However, length significantly enhances viewpoint diversity (article-based measurement) just 
in the case of large articles, and it is not significant for the newspaper-based viewpoint diversity measurement. Hence, we must reject Hypothesis 1b. The type of article matters in determining actor diversity measured at the article level, but it appears to be uninfluential in shaping actor diversity at the newspaper level. Also, the article's type does not have any impact on viewpoint diversity, which leads us to reject Hypothesis 2. Moving to the influences at the meso-level, the results show that the size of a newspaper, gauged by looking at its national/local geographical scope, matters in enhancing actor diversity measured at the newspaper level, but it is not significant for article-based scores. We therefore reject Hypothesis 3. Still, in line with Hypothesis 4a, we show that the orientation of newspapers towards a more highbrow audience matters in enhancing actor diversity, both for its articleand newspaper-based measurement. The elite/popular distinction, nonetheless, does not predict variation in viewpoint diversity, thus Hypothesis $4 \mathrm{~b}$ must be rejected. In general, viewpoint diversity seems harder to explain than actor diversity.

Finally, moving to the analysis of inter-country differences, it is worth noting that immigration news in each country of the sample is mostly domestic (more than $60 \%$ of total news items in Belgium and Italy deal with domestic immigration issues, more than $80 \%$ of the articles in Germany and the UK). Hence, different aspects of the broader theme of immigration are covered in each country of the sample. In Belgium and Germany, immigration news mainly presents stories related to asylum seekers, most of them coming from Afghanistan, whereas Italian newspaper focus on the entrance of African migrants by sea through Lampedusa, as well as on their stay in detention centres. By contrast, British outlets mainly cover stories of immigrant workers from Eastern Europe, and they give more space to frauds involving immigrants (e.g. sham marriages). Nonetheless, we observe that accidents involving migrants crossing the Mediterranean Sea can garner international media attention. In particular, the shipwreck of a migrant boat in Lampedusa in October 2013, causing the death of more than 300 immigrants, was widely covered by newspapers in all four countries under study.

Moreover, our results give some interesting insights into inter-country differences in terms of content diversity. When comparing articles of the same size, Table 2 shows that Italian newspapers present significantly higher levels of actor diversity $(p<.01)$ and viewpoints diversity $(\mathrm{p}<.01)$, whereas there are no significant differences among the other countries. A closer look to the Italian sample provides an indication that articles about Lampedusa are the most diverse. In line with the idea of Cuttitta (2014), Lampedusa is a "busy figurative stage" populated by the main actors with a stake in the immigration debate: immigrants arriving in Lampedusa after a perilous sea cross, national and EU politicians, who propose solutions to prevent the death of immigrants at sea, local politicians (like the mayor of Lampedusa, a key figure in the news), military actors from the guardia costiera (guardcoast) in charge of saving the migrants, often assisted by NGOs (e.g. the Red Cross). Very often, religious actors - including the Pope, who visited Lampedusa in July 2013 -, participate in the Italian mediated debate on Lampedusa, adding up to actor diversity and increasing, together with the other actors, the reporting of diverse viewpoints on immigration. Yet, the results show this "potential" of Italian newspapers to provide more content diversity remains somehow untapped: when length is not held constant, Italian newspapers present the least diverse coverage of the issue, whereas German outlets provide a significantly higher level of actor diversity $(\mathrm{p}<.05)$. Besides supporting the idea that the Italian style of reporting is less inclined to provide a diverse content (Esser and Umbricht 2013), this result suggests that length might be a crucial element through which journalists in Democratic-Corporatist countries can guarantee at least the diversity of actors talking in the news - as it is the case with German articles in our study. 


\section{Conclusions and Discussion}

By measuring actor and viewpoint diversity both at the article and at the newspaper level, this study explores and tries to explain content diversity in immigration news in four European countries (2013-2014). On the one hand, we have shown that the range of actors and viewpoints represented in an article is very limited, with about half of the articles giving voice to one type of actor and two thirds presenting only one type of viewpoint. On the other hand, the measurements of content diversity at the newspaper level yield a picture of high actor and viewpoint diversity for the period under study, meaning that over a longer period of time all social actors and viewpoints get at least some attention. Hence, content diversity measurements at the article and the newspaper yield different results. Yet, as the findings show, these measurements are weakly positively correlated. Newspapers that have on average more diverse articles also score higher on content diversity at the outlet level. But the correlation is far from perfect. This has probably to do with the diverging strategies of newspapers. While some try to provide content diversity in a single article, others provide this by spreading actors and viewpoints over multiple articles over a longer period of time.

We also find that both measurements vary according to the impact of different factors in a similar - yet not identical - way. In this sense, this paper sheds light on the conditions under which the ideal of a "marketplace of ideas" in the news can be fostered. First of all, the size of articles is a crucial factor in shaping content diversity, and particularly actor diversity: longer articles provide more space to represent a broader range of actors and viewpoints in the news, and they facilitate a more even distribution of social actor categories within the newspaper. Similarly, special reports, that provide a more in-depth account of immigration, provide more space for the representation of different actors, while the less objective nature of opinionated article types makes them less suitable to enlarge the range of actors in the articles. These article features are clearly connected to the different type of newspapers. Elite newspapers seem to cater to the "omnivorous" tastes of their target audiences with the representation of more social actors in the news, while popular outlets let a fewer categories talk. By contrast, the size of a newspaper, based on its national or local geographical scope, seems to enhance levels of actor diversity in the long term - while it has no effect on the diversity of a single article -, going against the argument of Voakes et al. (1996) that smaller news organisations present more actor diversity because they make extensive use of wireservices, which are used to contact multiple sources.

These findings seem to hold across countries - even when testing separately per each country - and suggest a more general pattern of how journalists report on immigration in Western democracies. The differences in content diversity between the four countries are minimal at best. This means that how journalists work and cover an issue such as immigration in these West European democracies is highly comparable and driven by similar news values and news routines. There is some proof that geographic proximity to the key locations where an issue is mainly unfolding (like it is the case with Italy and Lampedusa) might enhance content diversity. However, these results are sensitive to one of the main limitations of this study, namely the sample size. Further research on news content diversity should extend both the newspaper sample, in order to increase the statistical power of the test on content diversity measurements at the newspaper level, and the country sample, so that it can further investigate cross-country differences in the levels of content diversity. Moreover, the analysis should ideally also include a broader range of media types, such as television and online news, as they are for a large part of the public important sources of information about immigration. A more fundamental challenge for further research is the need for an empirical benchmark to evaluate the diversity of news content. The normative ideal of diversity is not 
enough to judge when a medium presents sufficient voices or viewpoints. Probably a more indepth study of news coverage of different media outlets can provide the necessary input.

To sum up, we conclude that at the level of a newspaper, across countries, there is an overall good performance in terms of diversity of type of actors and viewpoints. However, we have to think that they represent the distribution of actors and viewpoints in a newspaper over the period of time. In this sense, there can be cumulative benefits for a loyal newspaper reader. But on a regular day, in which on average one article on immigration is published, the reader will just be confronted with a limited number of voices and viewpoints. A closer look at the different voices that enter the news yield a somehow more negative picture of the performance of media when covering immigration. Immigrants, the main characters of immigration news, are mostly relegated to a secondary role as "silent victims". When reading an article, the odds that the reader will hear their voice is low. Also, when viewpoints are expressed, they will mostly portray them as victims. This means that immigrants face a double challenge: they have a hard time to enter the news arena; and when they enter, they have to try to emancipate from their depiction as "helpless victims".

\section{References}

Altheide, David L. 1985. "Impact of Format and Ideology on TV News Coverage of Iran." Journalism Quarterly 62 (2): 346-51.

Baker, C. Edwin. 2002. "Media Concentration: Giving up on Democracy." Fla. L. Rev. 54: 839-902.

Baden, Christian, and Nina Springer. 2015. "Conceptualizing viewpoint diversity in news discourse." Journalism 18 (2): 176-194.

Barnhurst, Kevin G., and John Nerone. 2001. The form of news: A history. New York: Guilford Press.

Baron, David P. 2006. "Persistent Media Bias." Journal of Public Economics 90 (1): 1-36.

Benson, Rodney. 2009. "What Makes News More Multiperspectival? A Field Analysis." Poetics 37 (5): 402-418.

- 2013. Shaping Immigration News: A French-American Comparison. Cambridge: Cambridge University Press.

Benson, Rodney, and Tim Wood. 2015. "Who Says What or Nothing at All? Speakers, Frames, and Frameless Quotes in Unauthorized Immigration News in the United States, Norway, and France." American Behavioral Scientist 59 (7): 802-821.

Berkowitz, Dan. 1987. "TV News Sources and News Channels: A Study in AgendaBuilding." Journalism Quarterly 64 (2-3): 508-13.

Bourdieu, Pierre. 1996. Sur la télévision suivi de L'emprise du journalisme. Paris: Paris, Liber, Raisons.

Bourdieu, Pierre, and Loïc Wacquant. 1992. An invitation to reflexive sociology. Chicago: University of Chicago press.

Callaghan, Karen, and Frauke Schnell. 2001. "Understanding the Consequences of Group Labeling for the Women's Movement." Women \& Politics 23 (4): 31-60. 
Carpenter, Serena. 2010. "A Study of Content Diversity in Online Citizen Journalism and Online Newspaper Articles." New Media \& Society 12 (7): 1064-84.

Choi, Jihyang. 2009. "Diversity in Foreign News in US Newspapers before and after the Invasion of Iraq." International Communication Gazette 71 (6): 525-542.

Cuttitta, Paolo. 2014. "'Borderizing' the Island Setting and Narratives of the Lampedusa 'Border Play'". ACME: An International Journal for Critical Geographies. 13 (2): 196-219.

De Swert, Knut, Laura Schacht, and Andrea Masini. 2015. "More than Human Tragedy? A Quantitative Comparison of Newspaper Coverage on Irregular Migration and Lampedusa in Five European Countries." Italian Studies 70 (4): 506-20.

DiMaggio, Paul. 1991. "Social structure, institutions, and cultural goods: The case of the United States." Social theory for a changing society, 133-55.

Esser, Frank, and Andrea Umbricht. 2013. "Competing Models of Journalism? Political Affairs Coverage in US, British, German, Swiss, French and Italian Newspapers.” Journalism 14 (8): 989-1007.

Franklin, Bob, and David Murphy. 1998. Making the local news: Local journalism in context. London: Routledge.

Gans, Herbert J. 1979. Deciding What's News: A Study of CBS Evening News, NBC Nightly News, Newsweek, and Time. Evanston, IL: Northwestern University Press. . 2011. "Multiperspectival News Revisited: Journalism and Representative Democracy." Journalism 12 (1): 3-13.

Gentzkow, Matthew, and Jesse M. Shapiro. 2006. "What Drives Media Slant? Evidence from US Daily Newspapers.” Econometrica 78 (1): 35-71.

Griswold, William F. 1998. "Shaping the News Mirror: Community Structure, Reporter Specialization and Content Diversity." In Mass Media, Social Control, and Social Change: A Macrosocial Perspective, edited by David Demers \& Kasisomayajula Viswanath, 183-196. Ames: Iowa State University Press.

Hallin, Daniel C., and Paolo Mancini. 2004. Comparing Media Systems: Three Models of Media and Politics. Cambridge: Cambridge University Press.

Hamilton, James. 2004. All the News That's Fit to Sell: How the Market Transforms Information into News. Princeton, NJ: Princeton University Press.

Holsti, Ole R. 1969. Content analysis for the social sciences and humanities. Reading, MA: Addison-Wesley.

Humprecht, Edda, and Florin Büchel. 2013. "More of the Same or Marketplace of Opinions? A Cross-National Comparison of Diversity in Online News Reporting." The International Journal of Press/Politics 18 (4): 436-461.

Levine, Donald N. 1988. The Flight from Ambiguity: Essays in Social and Cultural Theory. Chicago: University of Chicago Press.

Martin, Shannon Rossi. 1988. "Proximity of Event as Factor in Selection of News Sources." Journalism Quarterly 65 (4): 986-89.

Mcdonald, Daniel G., and John Dimmick. 2003. "The Conceptualization and Measurement of Diversity." Communication Research 30 (1): 60-79.

McQuail, Denis, and Jan J. Van Cuilenburg. 1983. "Diversity as a Media Policy Goal: A Strategy for Evaluative Research and a Netherlands Case Study." Gazette (Leiden, Netherlands) 31 (3): 145-62.

Napoli, Philip M. 1999. "Deconstructing the Diversity Principle.” Journal of Communication 49 (4): 7-34.

Patterson, Thomas E. 1998. "The political roles of the journalist." In The Politics of News; The News of Politics, edited by Doris Graber, Denis McQuail and Pippa Norris, 2339. Washington, DC: CQ Press. 
Peterson, Richard A., and Roger M. Kern. 1996. "Changing Highbrow Taste: From Snob to Omnivore.” American Sociological Review, 900-907.

Postman, Neil. 1985. Amusing Ourselves to Death. New York: Viking.

Reese, Stephen D. 2001. "Understanding the Global Journalist: A Hierarchy-of-Influences Approach." Journalism Studies 2 (2): 173-87.

Roggeband, Conny, and Rens Vliegenthart. 2007. "Divergent Framing: The Public Debate on Migration in the Dutch Parliament and Media, 1995-2004." West European Politics 30 (3): 524-548.

Sartori, Giovanni. 1997. Homo videns. Televisione e post-pensiero. Roma: Laterza.

Shoemaker, Pamela and Stephen Reese. 1996. Mediating the Message: Theories of Influences on Mass Media Content. White Plains, NY: Longman.

Van Cuilenburg, Jan. 1999. "On Competition, Access and Diversity in Media, Old and New Some Remarks for Communications Policy in the Information Age." New Media \& Society 1 (2): 183-207.

Van Gorp, Baldwin. 2005. "Where Is the Frame? Victims and Intruders in the Belgian Press Coverage of the Asylum Issue." European Journal of Communication 20 (4): 484507.

Voakes, Paul S., Jack Kapfer, David Kurpius, and David Shano-yeon Chern. 1996. "Diversity in the News: A Conceptual and Methodological Framework." Journalism \& Mass Communication Quarterly 73 (3): 582-593. 


\section{Figure 1}

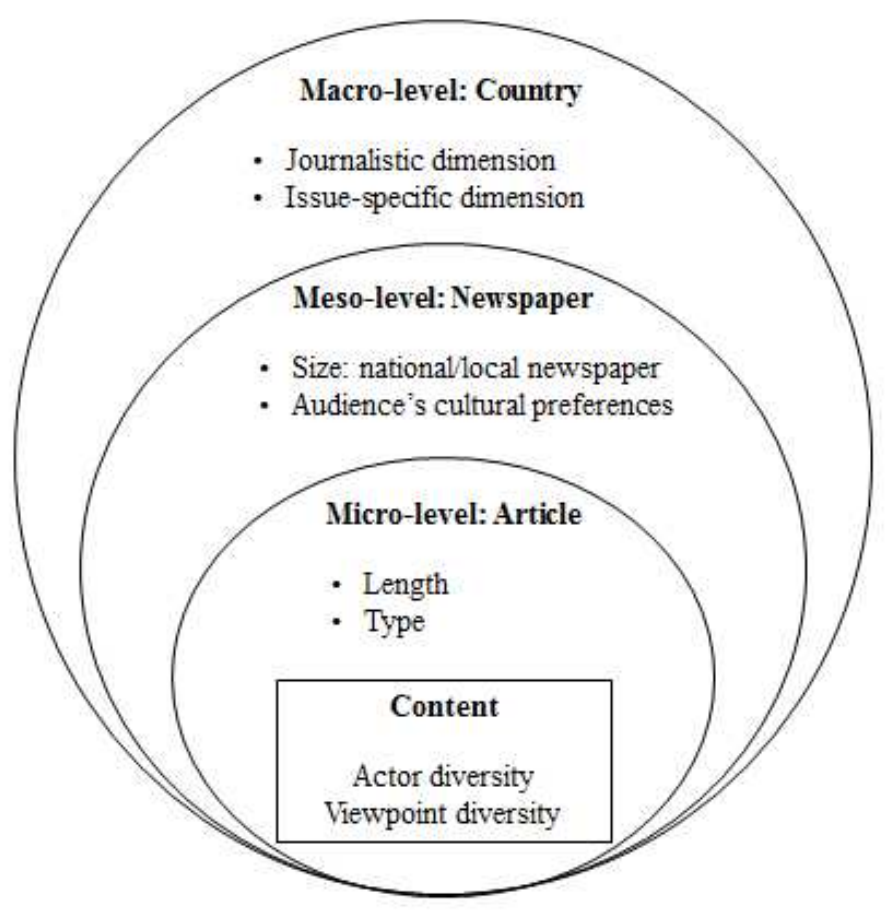

Figure 1 - Multilevel Model of Influence on Content Diversity 


\section{Graph 1}

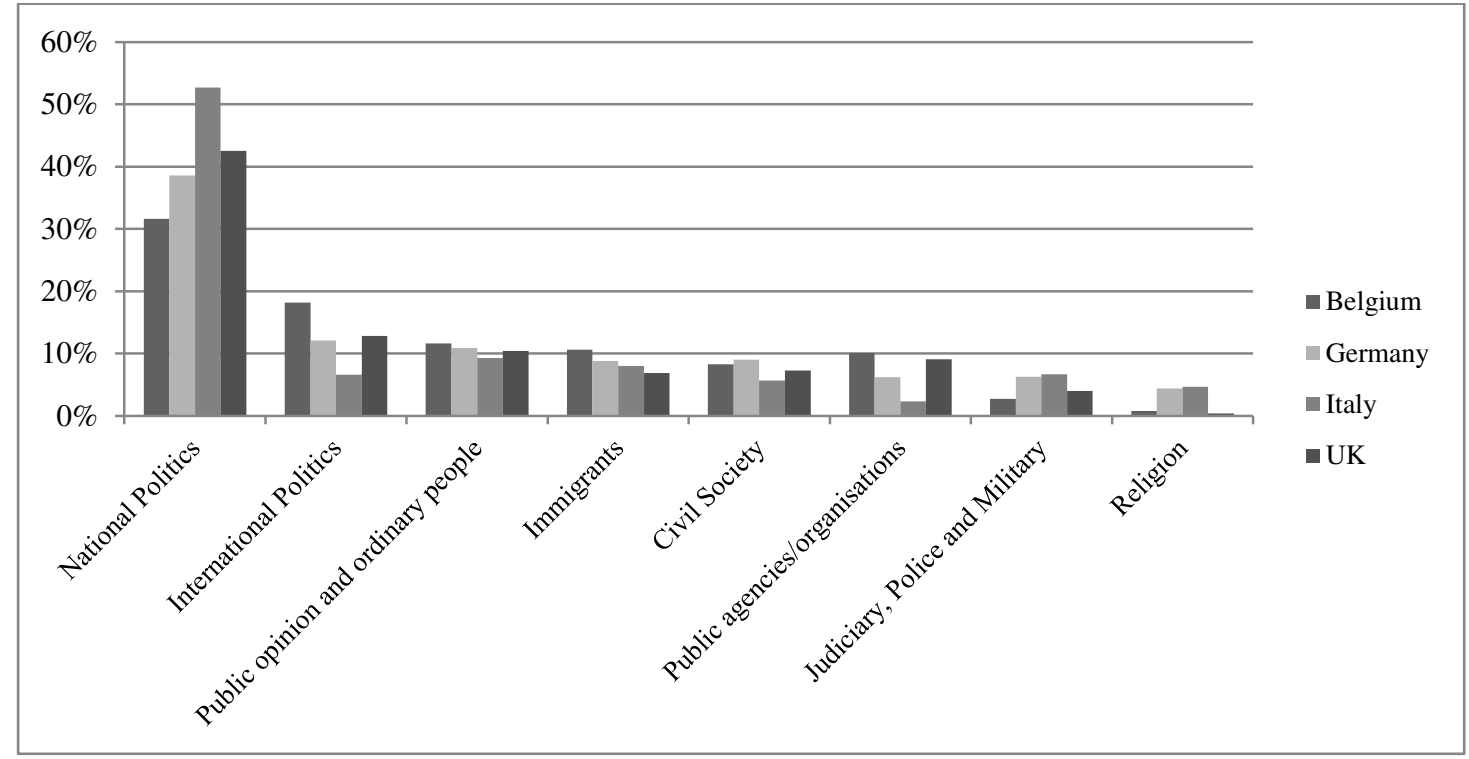

Graph 1 - Distribution of actor categories across countries, $N=6863$ (Belgium, $N=1679$; Germany, $N=1625$, Italy, $N=$ 1932 , UK = 1627). The graph does not include the following categories, which were underrepresented in the sample: Business/Corporate/Finance, Journalists and media celebrities, Traffickers/Smugglers. 
Table 1

\begin{tabular}{|c|c|c|c|c|c|}
\hline & & \multicolumn{2}{|c|}{ Actor diversity } & \multicolumn{2}{|c|}{ Viewpoint diversity } \\
\hline & & $\begin{array}{l}\text { Average actor } \\
\text { categories per } \\
\text { article }\end{array}$ & $\begin{array}{l}\text { Average } D_{\mathrm{z}} \\
\text { actors }\end{array}$ & $\begin{array}{l}\text { Average } \\
\text { viewpoint } \\
\text { categories per } \\
\text { article }\end{array}$ & $\begin{array}{l}\text { Average } D_{\mathrm{z}} \\
\text { viewpoints }\end{array}$ \\
\hline \multirow{4}{*}{$\begin{array}{l}\text { Articles' } \\
\text { characteristics: } \\
\text { Length }\end{array}$} & $\begin{array}{l}\text { Very short articles } \\
(\mathrm{N}=590)\end{array}$ & 1.38 & \multirow{2}{*}{0.77} & 1.28 & \multirow{2}{*}{0.86} \\
\hline & $\begin{array}{l}\text { Short articles } \\
(\mathrm{N}=840)\end{array}$ & 1.68 & & 1.33 & \\
\hline & $\begin{array}{l}\text { Medium articles } \\
(\mathrm{N}=496)\end{array}$ & 1.87 & \multirow{2}{*}{0.86} & 1.36 & \multirow{2}{*}{0.91} \\
\hline & $\begin{array}{l}\text { Long articles } \\
(\mathrm{N}=564)\end{array}$ & 2.37 & & 1.51 & \\
\hline \multirow[t]{3}{*}{ Type } & $\begin{array}{l}\text { News reports } \\
(\mathrm{N}=1698)\end{array}$ & 1.80 & & 1.33 & \\
\hline & $\begin{array}{l}\text { Opinionated news } \\
\text { types } \\
(\mathrm{N}=523)\end{array}$ & 1.52 & 0.80 & 1.42 & 0.87 \\
\hline & $\begin{array}{l}\text { Special reports } \\
(\mathrm{N}=245)\end{array}$ & 2.57 & 0.83 & 1.51 & 0.89 \\
\hline \multirow{2}{*}{$\begin{array}{l}\text { Newspapers' } \\
\text { characteristics: } \\
\text { Circulation share }\end{array}$} & $\begin{array}{l}\text { Local } \\
(\mathrm{N}=731)\end{array}$ & 1.82 & 0.78 & 1.39 & 0.93 \\
\hline & $\begin{array}{l}\text { National } \\
(\mathrm{N}=1759)\end{array}$ & 1.84 & 0.83 & 1.36 & 0.86 \\
\hline \multirow{2}{*}{$\begin{array}{l}\text { Audience's } \\
\text { cultural } \\
\text { preferences }\end{array}$} & $\begin{array}{l}\text { Popular } \\
(\mathrm{N}=721)\end{array}$ & 1.63 & 0.78 & 1.34 & 0.88 \\
\hline & $\begin{array}{l}\text { Elite } \\
(\mathrm{N}=1769)\end{array}$ & 1.90 & 0.85 & 1.38 & 0.90 \\
\hline \multirow[t]{4}{*}{ Countries } & $\begin{array}{l}\text { Articles in Belgium } \\
(\mathrm{N}=642)\end{array}$ & 1.81 & 0.87 & 1.31 & 0.89 \\
\hline & $\begin{array}{l}\text { Articles in Germany } \\
(\mathrm{N}=484)\end{array}$ & 2.06 & 0.85 & 1.40 & 0.89 \\
\hline & $\begin{array}{l}\text { Articles in Italy } \\
(\mathrm{N}=822)\end{array}$ & 1.68 & 0.75 & 1.39 & 0.83 \\
\hline & $\begin{array}{l}\text { Articles in the UK } \\
(\mathrm{N}=542)\end{array}$ & 1.87 & 0.82 & 1.40 & 0.93 \\
\hline
\end{tabular}

Table 1 - Mean of actor and viewpoint diversity (calculated at the article and newspaper level) per newspapers' and articles' characteristics, including cross-country variance. Total articles $\mathrm{N}=2490$. 


\section{Table 2}

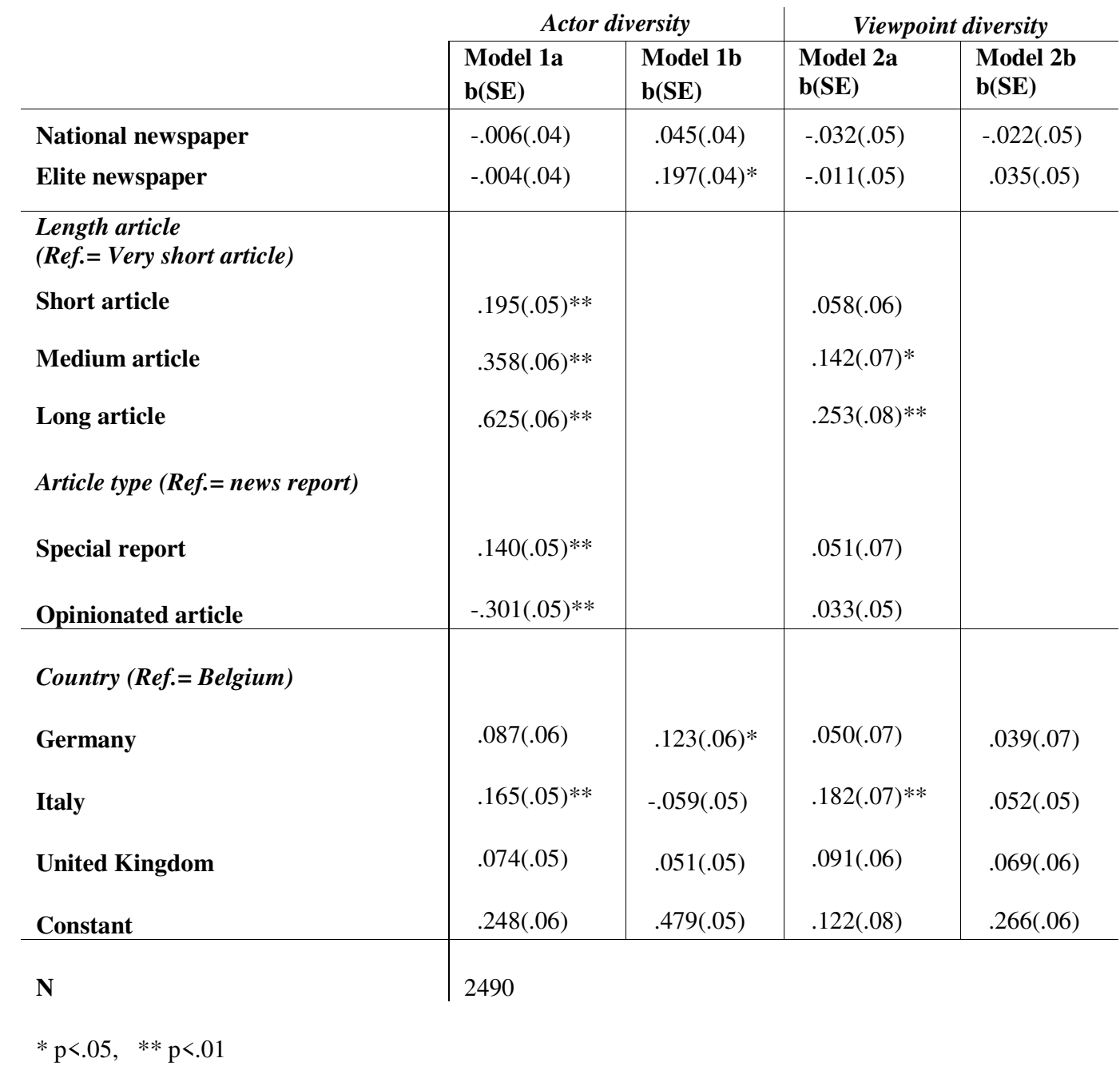

Table 2 - Results of the multilevel regression model on actor diversity 


\section{Appendix}

\begin{tabular}{|c|c|c|c|}
\hline Newspaper & Country & Audience's cultural orientation & Geographical scope \\
\hline De Morgen & Belgium & Elite (Highbrow) & National* \\
\hline de Standaard & Belgium & Elite (Highbrow) & National* \\
\hline De Tijd & Belgium & Elite (Highbrow) & National* \\
\hline Gazet van Antwerpen & Belgium & Popular (Middlebrow) & Local \\
\hline Het Nieuwsblad & Belgium & Popular (Middlebrow) & National* \\
\hline Het Laatste Nieuws & Belgium & Popular (Middlebrow) & National* \\
\hline Die Welt & Germany & Elite (Highbrow) & National \\
\hline Berliner Morgenpost & Germany & Elite (Highbrow) & Local \\
\hline Der Tagesspiegel & Germany & Elite (Highbrow) & Local \\
\hline Süddeutsche Zeitung & Germany & Elite (Highbrow) & National \\
\hline Stuttgarter Nachrichten & Germany & Elite (Highbrow) & Local \\
\hline La Repubblica & Italy & Elite (Highbrow) & National \\
\hline Gazzetta di Modena & Italy & Popular (Middlebrow) & Local \\
\hline Il Giornale & Italy & Popular (Middlebrow) & National \\
\hline Il Messaggero & Italy & Elite (Highbrow) & National \\
\hline Il Mattino & Italy & Elite (Highbrow) & Local \\
\hline The Times & UK & Elite (Highbrow) & National \\
\hline The Independent & UK & Elite (Highbrow) & National \\
\hline The Sun & UK & Popular (Lowbrow) & National \\
\hline Daily Mirror & UK & Popular (Lowbrow) & National \\
\hline Manchester Evening News & UK & Popular (Middlebrow) & Local \\
\hline London Evening Standard & UK & Popular (Middlebrow) & Local \\
\hline
\end{tabular}

Appendix 1 - Newspaper sample's characteristics

* Since Belgium has no national papers that cover the whole bilingual country, we label outlets that cover the whole Flemish media landscape as national. These newspapers have higher interests for federal issues, and they clearly have a broader scope compared to more local newspapers - like Gazet van Antwerpen -, which are usually the newspapers of a region (province). 